Elsevier required licence: $(c)<2018>$. This manuscript version is made available under the CC-BY-NC-ND 4.0 license http://creativecommons.org/licenses/by-nc-nd/4.0/ 


\title{
Functional evaluation of pollutant transformation in sediment from combined sewer system*
}

\author{
Xuan Shi ${ }^{a}$, Huu Hao Ngo ${ }^{\text {, }}$ Langtao Sang ${ }^{a}$, Pengkang Jin ${ }^{a,}{ }^{*}$, Xiaochang C. Wang ${ }^{\text {a }}$ \\ Guanghua Wang ${ }^{\mathrm{C}}$ \\ a School of Environmental and Municipal Engineering, Xi'an University of Architecture and Technology, Xi'an, Shaanxi Province, 710055, China

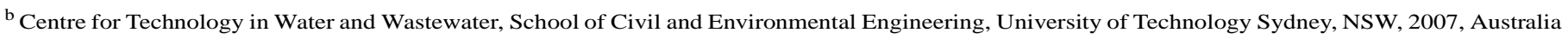 \\ c Guangzhou Municipal Engineering Design \& Research Institute, Guangzhou, Guangdong Province, 510060, China \\ * Corresponding author. E-mail addresses: pkjin@hotmail.com, pkjin@xauat.edu.cn (P. Jin).
}

\begin{abstract}
In this study, a pilot combined sewer system was constructed to characterize the pollutant trans- formation in sewer sediment. The results showed that particulate contaminants deposited from sewage could be transformed into dissolved matter by distinct pollutant transformation pathways. Although the oxidation-reduction potential (ORP) was varied from $-80 \mathrm{mV}$ to $-340 \mathrm{mV}$ in different region of the sediment, the fermentation was the dominant process in all regions of the sediment, which induced hydrolysis and decomposition of particulate contaminants. As a result, the accumulation of dissolved organic matter and the variation of ORP values along the sediment depth led to the depth-dependent reproduction characteristics of methanogens and sulfate-reducing bacteria, which were existed in the middle and deep layer of the sediment respectively. However, the diversity of nitrifying and polyphosphateaccumulating bacteria was low in sewer sediment and those microbial communities showed a non-significant correlation with nitrogen and phosphorus contaminants, which indicated that the enrichment of nitrogen and phosphorus contaminants was mainly caused by physical deposition process. Thus, this study proposed a promising pathway to evaluate pollutant transformation and can help provide theoretical foundation for urban sewer improvement.
\end{abstract}

\section{Keywords}

Urban sewer system; Sewer sediment regions; Distribution characteristics of microbial communities; Pollutant transformation Environmental factors

\section{Introduction}

Sewer systems, an important component of urban infrastructure, are used to collect and transport sewage. In recent decades, according to the design criteria, sewer systems are designed as either combined or separated sewer systems, and due to the economic and technological conditions, combined sewer systems are mainly implemented in older and under-developed cities (Chhetri et al., 2016). Due to the collection requirements of residential wastewater, industrial wastewater and rainwater (Liu et al., 2015), the sewer pipe diameter in combined sewers is much larger than that in separated sewer systems, which results in that the sewage is transported at a low flow velocity in normal weather (JalliffierVerne et al., 2016). Therefore, particulate matter deposition occurs and generates the formation of sewer sediment in the sewer
(Ashley et al., 2003), and the study showed that 30e500 g of particulate matter was deposited per meter length of the sewer per day. Furthermore, to clarify the sediment transport process, diverse models of these physical processes were established (Skipworth et al., 1999; Mouri and Oki, 2010). Previous studies have mainly focused on physical deposition processes, while these studies did not reveal the change of the properties and characterize the transformation mechanism of sediment, where the complex reactions might occur in urban sewer systems.

Many urban sewers are under the dark and anaerobic environment (Jin et al., 2015), and the abundant particulate matter depositing from sewage could induce the accumulation of substrate in sewer sediment. All the conditions mentioned above in sewer sediment are the same as the anaerobic wastewater treatment systems where the diverse matters were decomposed, therefore, it could be inferred that the same bioreactions might be also occurred in sewer sediment. Previous studies have shown that bioproduction of sulfide and methane cannot be ignored in sediment (Liu et al., 2015), and it indicated the small organic molecules which 
were utilized by methanogens and sulfate-reducing bacteria might be abundant in the sewer sediment. In fact, the processes of methanogenesis and sulfate reduction mainly consume acetic acid and propionic acid (Pender et al., 2004; Muyzer and Stams, 2008), while the formation of sewer sediment is mainly attributed to particulate matter deposition. Therefore, diverse particulate matter hydrolysis processes must occur in the sediment that produce abundant, easily degradable substrates. The conversion of particulate matter mainly results from the reproductive processes of homologous microbial communities, and in addition to the utilization of carbon substrates, the bioreactions generally involve the transformation of nitrogen and phosphorus matters, which has been also verified in anaerobic wastewater treatment systems (Tabatabaei et al., 2010). Accordingly, significant decomposition of these contaminants may occur under the similar anaerobic conditions of sewer sediment. However, to our best knowledge, although the WATS and the SeweX models (Hvitved-Jacobsen et al., 1998; Sharma et al., 2008) were proposed to evaluate biological reactions in sediment, those models only predicted the bioreactions occurred in biofilms, and the understanding of diverse matters transformation in sewer sediment is poor. Due to the potential risks of poisonous gas emission and corrosion as well as the effect on the influent quality of wastewater treatment plants caused by those biochemical reactions, it is necessary to gain a better understanding of pollutant transformation processes in sewer sediment.

In order to reveal the unknown mechanism mentioned above, a pilot experimental sewer system was established to discover the pollutant transformation pathways in different longitudinal profiles and depths of sewer sediment. By using high-throughput sequencing, the microbial community distribution in the inner sediment was characterized. Considering the effect of environmental factors e.g. oxidation and reduction potential (ORP), correlations between the pollutants and functional bacteria in different regions of the sediment were established. Therefore, a promising method to analyze and predict pollutant transformation in sewers was proposed, which can be a reliable guideline for urban sewer improvement and the prevention of urban accidents in sewer systems.

\section{Materials and methods}

\subsection{Sewer system operation and sample collection}

The simulated sewer system constructed for this study is shown in Fig. 1(a). The total effective length of this sewer was $32 \mathrm{~m}$, and the diameter of the pipe was $200 \mathrm{~mm}$. The different layers were connected by a cylindrical inspection well that was 400 $\mathrm{mm} \times 600 \mathrm{~mm}$. The sewage was raised to the top layer by a submersible pump from a cyclic water tank, and the sewage flowed to the bottom layer via gravity. To fully simulate the gravity flow state of an urban sewer, the simulated sewer was designed with a slope of $5 \%$. The inner surface of the pipe was polished to simulate real pipes and to ensure the proper resistance coefficient and Reynolds number in the sewer system. The sewage was collected from wastewater treatment plant in Xi'an, China, in addition, the particulate matters which deposited from sewage induced the formation of sediment in $180 \mathrm{~d}$, and then the pollutant transformation and microbial community distribution were detected in $60 \mathrm{~d}$.

To evaluate the diverse pollutant transformation characteristics, sediment samples were collected in seven regions of the sewer sediment at seven different times $(1,10,20,30,40,50,60$ day at the operation process of pilot sewer system) (Fig. 1(b)). When the sewer sediment was sampled, two perspex sheets (semicircle and the size was the same as the pilot sewer pipe) were used to insert the sewer sediment (the distance between two perspex sheets was $3 e 5 \mathrm{~cm}$ ), and then pick up a longitudinal section of sediment which could guarantee that the sediment structure were not damaged. One of the perspex sheets were drilled in advance, and the positions of holes were same as the seven sampling position in sediment (shown in Fig. 1(b)), therefore, after the sediment was picked up, the target sewer sediment could be taken out from the seven holes in the perspex sheet.

\subsection{Chemical analysis}

Total chemical oxygen demand, nitrogen and phosphorus were measured in accordance with standard methods (APHA et al., 2002). All sludge samples were filtered through a $0.45 \mathrm{~mm}$ filter before SCOD detection. The ORP of sediment was measured by a HQ30d meter (HACH. USA). The methane and hydrogen sulfide was measured by a GC310 meter (China).

SCFAs and $\mathrm{CH}_{4}$ were measured by gas chromatography. For the detection of short-chain fatty acids (SCFAs): Phosphoric acid (3\%) was dropwise added to regulate the $\mathrm{pH}$ of the samples to approximately 4 . The SCFAs concentration was characterized by the COD concentration: 1.07 for acetic acid, 1.51 for propionic acid, 1.82 for butyric and isobutyric acid, and 2.04 for valeric and isovaleric acid (Feng et al., 2009).

\subsection{Illumina high-throughput sequencing}

\subsubsection{Extraction of genome DNA}

The total genome DNA was extracted from the samples using the CTAB/SDS method. The DNA concentration and purity was monitored on $1 \%$ agarose gels. According to the concentration, the DNA was diluted to $1 \mathrm{ng} / \mathrm{ml}$ using sterile water.

\subsubsection{Amplicon generation}

The sludge samples were sent to the Novogene Institute (Beijing,

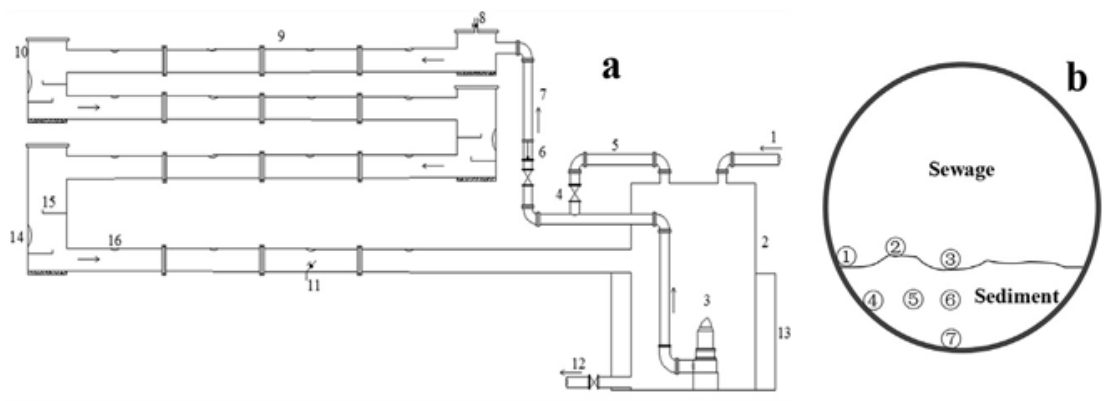

Fig. 1. Experimental setup. (a) Schematic representation of the simulated sewer system (b) Schematic view of sample collection regions in the sewer pipe. 
China) for Illumina high-throughput sequencing on a HiSeq 2000 platform (Illumina, USA). Primers 515F-806R were used to target the V3-V4 region of the 16S SSU rRNA. All PCR reactions were carried out in $30 \mathrm{~mL}$ volumes with $15 \mathrm{~mL}$ of Phusion ${ }^{\circledR}$ High-Fidelity PCR Master Mix (New England Biolabs), $0.2 \mathrm{mM}$ of forward and reverse primers, and approximately $10 \mathrm{ng}$ of template DNA. Thermal cycling consisted of initial denaturation at $98^{\circ} \mathrm{C}$ for $1 \mathrm{~min}$, followed by 30 cycles of denaturation at $98^{\circ} \mathrm{C}$ for $10 \mathrm{~s}$, annealing at $50^{\circ} \mathrm{C}$ for $30 \mathrm{~s}$, and elongation at $72{ }^{\circ} \mathrm{C}$ for $30 \mathrm{~s}$. Finally, the samples were held at $72{ }^{\circ} \mathrm{C}$ for $5 \mathrm{~min}$.

\subsubsection{PCR products quantification and qualification}

The same volume of $1 \mathrm{X}$ loading buffer (contained SYB green) and PCR products were mixed, and electrophoresis was operated on $2 \%$ agarose gel for detection. Samples with a bright main strip between 400 and 450 bp were chosen for further experiments.

\subsubsection{PCR products mixing and purification and library preparation} and sequencing

The PCR products were mixed in equidensity ratios. Then, the mixture of PCR products was purified with a GeneJET Gel Extraction Kit (Thermo Scientific). Sequencing libraries were generated using the Illumina TruSeq DNA PCR-Free Library Preparation Kit (Illumina, USA) following the manufacturer's recommendations and adding index codes. The library quality was assessed on a Qubit@ 2.0 Fluorometer (Thermo Scientific) and Agilent Bioanalyzer 2100 system. Finally, the library was sequenced on an Illumina HiSe platform, and 250 bp paired-end reads were generated.

\subsubsection{Sequencing data analysis}

Paired-end reads from the original DNA fragments were merged using FLASH (Mago and Salzberg, 2011) e a very fast and accurate analytical tool designed to merge paired-end reads when there are overlaps between reads1 and reads2. Paired-end reads was assigned to each sample according to the unique barcodes. Se- quences were analyzed using the QIIME software package (Quan- titative Insights Into Microbial Ecology) (Caporaso et al., 2010), and in-house Perl scripts were used to analyze alpha (within samples) and beta (among samples) diversity. First, the reads were filtered by QIIME quality filters. Then, we used pick_de_novo_otus.py to pick operational taxonomic units (OTUs) by creating an OTU table. Sequences with $97 \%$ similarity were assigned to the same OTUs. Observed Species estimate the amount of unique OTUs found in each sample, along with the Shannon index. Rarefaction curves were generated based on these three metrics. QIIME calculated both the weighted and unweighted UniFrac, which are phylogenetic measures of beta diversity. To further examine the microbial diversity and differences among the samples, significance tests were conducted with some statistical analysis methods.

\section{Results and discussion}

\subsection{Pollutant transformation characteristics in sewer sediment}

The transformation characteristics of carbon, nitrogen and phosphorus contaminants in the sediment are shown in Fig. 2(a)e(d). In urban sewer systems, the fastigium of sewage flow mainly occurs between 8:00 a.m. and 22:00 p.m.; therefore, the concentration of contaminants in the sediment was detected twice per day (at 8:00 a.m. and 22:00 p.m.). The TCOD concentration in the sewer sediment increased every day during the period of sewage flow and increased from 45,682 $\mathrm{mg} / \mathrm{L}$ to $54,160 \mathrm{mg} / \mathrm{L}$ (average values of $5 \mathrm{~m}, 13 \mathrm{~m}, 21 \mathrm{~m}$, and $29 \mathrm{~m}$ in the sewer) in $60 \mathrm{~d}$. The SCOD concentration showed an obvious increase at the initial time (from $364 \mathrm{mg} / \mathrm{L}$ to $461 \mathrm{mg} / \mathrm{L}$ ) and then gradually stabilized (from $461 \mathrm{mg} / \mathrm{L}$ to $480 \mathrm{mg} / \mathrm{L}$ ), which indicated that the decomposition of particulate matter occurred continuously in sewer sediment. The concentration of SCFAs increased first and then showed a slight decrease afterwards. This may be attributed to easy degradation of SCFAs, which could be utilized by fermentative and methane-producing microorganisms, therefore, the concentration of methane increased significantly over $60 \mathrm{~d}$ (Supporting Fig. 1). The concentration of $\mathrm{TN}$ and $\mathrm{NH}_{3}-\mathrm{N}$ increased to $111 \mathrm{mg} / \mathrm{L}$ and $47 \mathrm{mg} / \mathrm{L}$, respectively in $60 \mathrm{~d}$; nevertheless, $\mathrm{NO}_{3}-\mathrm{N}$ could not be detected in the sediment. The concentration of TP and $\mathrm{PO}_{4}-\mathrm{P}$ in the sediment showed the same increasing tendency with carbon and nitrogen (increased to $89 \mathrm{mg} / \mathrm{L}$ and $68 \mathrm{mg} / \mathrm{L}$, respectively). These results revealed that due to particulate matter deposition from the sewage, the carbon, nitrogen and phosphorus contaminant matters tended to be enriched in the sewer sediment, and in order to reveal the mechanism of those pollutant transformation, the correlation of different contaminants and microbial metabolism is illustrated in the following analysis.

\subsection{Microbial communities structure in the sewer sediment}

To gain an overview of the microbial community structure in the sewer sediment, seven regions of sediment mixtures in the sewer system were analyzed by high-throughput sequencing (the sampling locations are shown in Fig. 1(b)), and an average of 34,536 effective sequences were obtained. As shown in Fig. 3, GraPhlAn provides two main outputs, describing the abundant phylum taxa (including bacteria and archaea) in the sewer sediment and the phylogenetic distribution of these communities. The 40 most abundant taxonomic communities are exhibited by the colored circles, and the size of the circles describes the relative abundance of each community. Pyrosequencing of 16S rRNA genes showed that the dominant microbial communities were the Proteobacteria phylum with a relative abundance of $36.68 \%$, followed by Euryarchaeota (26.42\%), Bacteroidetes (11.94\%) and Firmicutes (8.79\%). It is known that Proteobacteria, Bacteroidetes and Firmicutes could exhibit fermentation capacity, which mainly included hydrolysis and acidification processes (Nelson et al., 2011; Lev'en et al., 2007); therefore, the enrichment of these microbial communities might lead to the decomposition of particulate matter, leading to SCOD increasing in the sewer sediments (in accordance with the results of Fig. 2(b)). Because the newly generated carbon source (easily degradable) could be a suitable substrate for methane producing, Euryarchaeota (including methanogens, which produce methane (Hogan, 2010)) could achieve propagation easily to become the dominant phylum of archaea in the sewer sediment. Methanosaeta was the most abundant genus of Euryarchaeota in the sewer sediment, which could produce an extensive amount of methane under anaerobic conditions, and they were the dominant microbial community for methane emission in sewers (Rotaru et al., 2014). With these active bioreactions, particulate carbon contaminants could easily be transformed in the sewer sediment. In addition, many types of denitrifiers are included in the Proteobacteria phylum (Chen et al., 2008; Srinandan et al., 2011), and the nitrification process, which enriches the concentration of nitrate, could be prohibited under the anaerobic environment in the sewer sediment; therefore, nitrate could not be detected in the sewer system (as shown in Fig. 2(c)).

\subsection{Microbial conversions in different regions of the sewer sediment}

The depth of the sewer sediment was approximately $60 \mathrm{~mm}$ in this study. Sewage flowing in the sewer at different velocities causes irregular disturbances in sediment; therefore, the diversity 

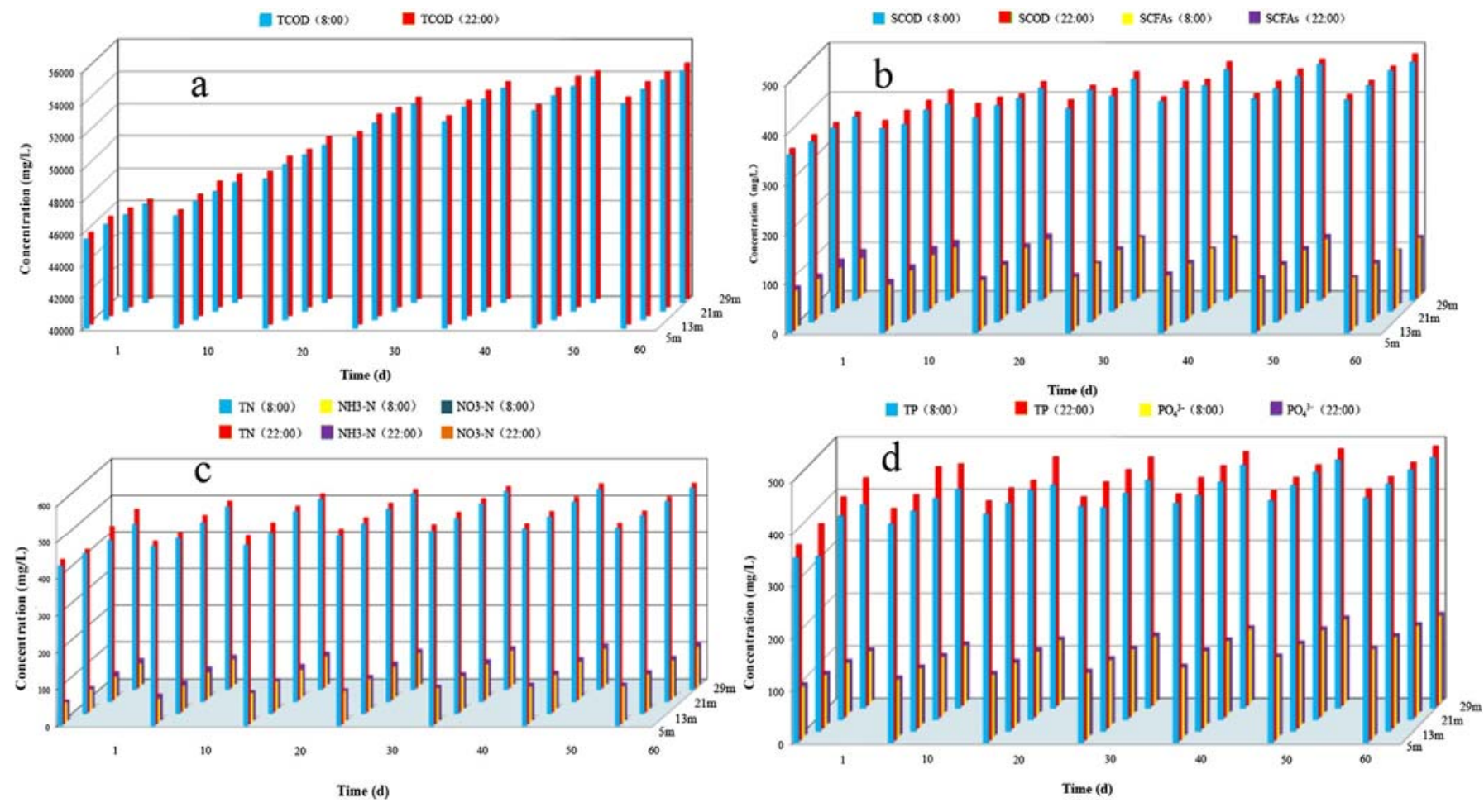

Fig. 2. Transformation of pollutant in the sewer system. (a), (b), (c), (d) pollutant transformation of carbon, nitrogen, phosphorus in the sewer.

of microbial communities in each layer of the sediment may be different. To verify this hypothesis, seven regions of sediment were sampled to detect the distribution of microbial communities. As shown in Fig. 4(a), there were 484 OTUs in common in the seven samples, and the majority of OTUs in samples (1), (2), (3), (4), (5), and (6) were basically same; nevertheless, the genera in sample (7) were significantly different from the others. To reveal the in-depth distribution characteristics of the dominant genera along the longitudinal profile of the sewer sediment, ternary diagrams (Fig. 4(b)e(d)) were conducted. Fig. 4(b) shows the relative proportion of dominant genera in samples (1), (4), and (7), which were taken from the inner surface of the sewer. Methanosaeta was abundant in sample (4) with a relative abundance of $29.86 \%$; nevertheless, the relative proportion of this genus was much lower in samples (1) and 7 ( $0.11 \%$ and $5.42 \%$, respectively). In fact, the relative proportions of the dominant genera were similar in samples (4), (5), and (6) (as shown in Fig. 4(c)), and Methanosaeta was the dominant genus in the middle layer of the sewer sediment (regions (4), (5), and (6)). In all regions of the sewer sediment, Smithella (a genus of propionate-oxidizing bacteria (EUZ'BY, 1997)) were a nonnegligible genus, which may promote the decomposition of carbon contaminants (Fig. 4(b)e(d)).

The typical fermentative bacteria such as Trichococcus, Cloacibacterium and Paludibacter (Dinh et al., 2014; Yassin et al., 2012; Luo et al., 2014) could be detected in most regions of sediment (Supporting Tables 1 and 2), which could induce the hydrolysis and acidification of particulate organic matters, however, the abundance of some fermentative bacteria which could transform macromolecular organic matters into SCFAs showed the decrease tend from middle layer to deep layer of sediment (Trichococcus, Cloacibacterium), and it indicated that the accumulation rate of small molecule organic substrate in deep layer would be lower than that in middle layer. However, Lactobacillus, a major part of the lactic acid producing bacteria (convert polysaccharide to lactic acid (Rao et al., 2000)) could only be detected in the region (7), meanwhile, due to the capacity of consuming lactic acid at the condition of low small molecule organic matters, the relative abundance of dominant sulfate reducting bacteria (SRB) (Desulfovibrio and Desulfobulbus (Supporting Tables 1 and 2) (Tsukamoto and Miller, 1999; Taylor and Parkes, 1983)) increased from $0.01 \%$ and $0.03 \%$ (upper layer of the sediment) to $1.70 \%$ and $0.97 \%$ (deep layer of the sediment). When the hydrogen sulfide (metabolites of SRB) enriched, a variety of microbial communities especially methanogens would be inhibited (Maillacheruvu et al., 1993; Henze and Harremo®s, 1983). It indicates that, due to the enrichment of sulfate-reducing bacteria, sulfide might be produced mainly in the deep layer of the sediment. The above mentioned results indicate that the environment of the sewer inner surface affects the reproduction of bacteria (different genera distribution characteristics between samples (1) and (4) but similar distribution of bacteria in samples (3) and (6)), and because fermentative bacteria were the dominant microbial community in all samples, carbon transformation was achieved in all regions of the sewer sediment. It should be noted that Methanosaeta (a genus of archaea) showed different distribution characteristics in the different layers; therefore, the archaea were analyzed individually in the samples.

The observed species numbers of archaea in the seven regions are exhibited in Fig. 5(a). Approximately 1400 species were observed in samples (4), (5), and (6), which is much higher than that in the other samples (500e900 species). The results showed that the diversity of archaea increased with the sediment depth, and reached a peak value in the middle layer before gradually reducing in the deeper layer. The observed species number in region (7) was slightly higher than that in regions (1), (2), and (3); which indicated the environment at the middle layer of the sewer sediment was suitable for the reproduction of archaea, and owing to the irregular disturbance of the sewage, the archaea could not accomplish normal metabolism processes at the surface of the sediment. Fig. 5(b) and (c) shows the relative proportions of the dominant archaea in different samples. In the middle layer (regions (4), (5), and 
A:C-Bacteroidia

B:0--Bacteroidales

C:C--Deltaproteobacteria

D:0--Syntrophobacterales

E:c--Betaproteobacteria

$\mathrm{F}: 0$-Burkholderiales

G:f--Comamonadaceae

H:O--Rhodocyclales

I:f--Phodocyclaceae

I:C-Epsilonproteobacteria

K:o--Campylobacterales

L:C-Gammaproteobacteria

M:O-.Pseudomonadales

N:f-Moraxellaceae

O:g--Acinetobacter

P:o-Oceanospirillales

Q:f--Halomonadaceae

R:g--Halomonas

S:0--Alteromonadales

T:f-Shewanellaceae

U:g--Shewanella

V:C-Alphaproteobacteria

W:C-unidentified Actinobacteria

$X: C-$ Clostridia

Y:0-Clostridiales

Z:0-Clostridiales

a:c--Synergistia

b:o--Synergistales

c:f--Synergistaceae

dic-Methanomicrobia

e:0-Methanosarcinales

f;f--Methanosaetaceae

g:g-Methanosaeta

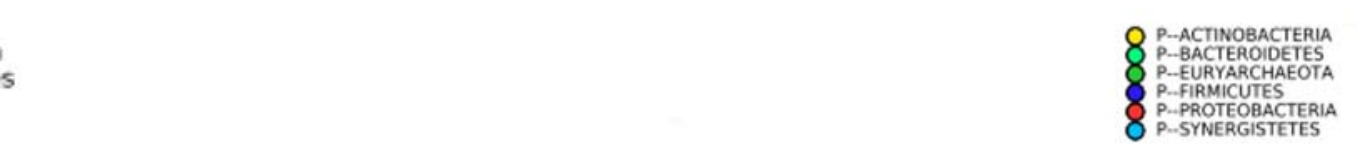

.
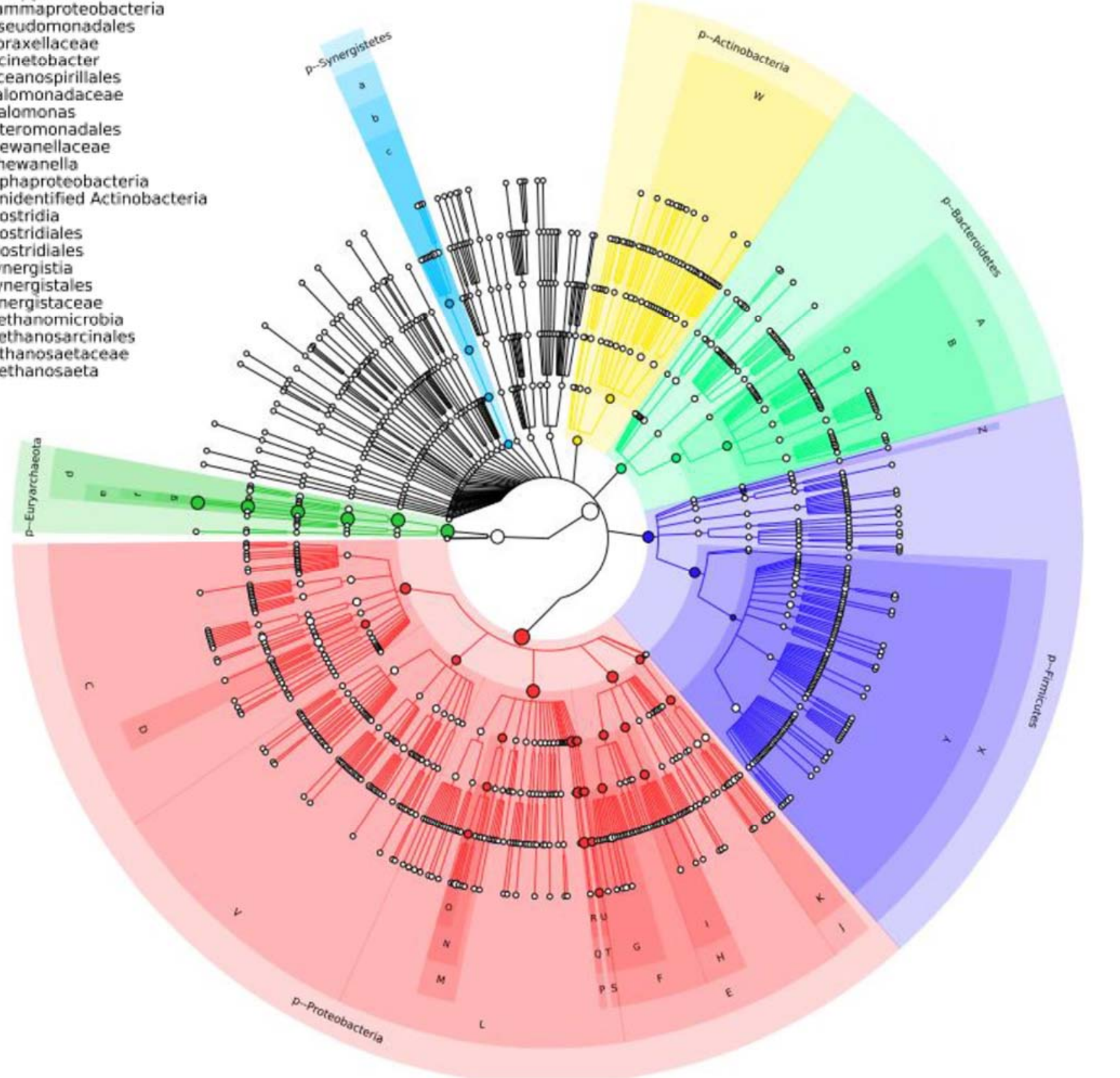

Fig. 3. Microbial community structure and phylogenetic tree of bacteria and archaea.

(6)), the species and relative proportions of the dominant archaea were almost the same (relatively equidistant distribution in the ternary diagram), and methane-producing archaea (Methanobacterium, Woesearchaeota and Lactivibrio (Ortiz-Alvarez and Casamayor, 2016; Qiu et al., 2014)) were enriched in this layer. In regions (3), (6), and (7) (the longitudinal profile of sewer sediment), the dominant methane-producing archaea were enriched in region
(6) rather than in regions (3) and (7). It could be concluded that methane emission in the sewer mainly resulted from the middle layer of the sediment.

To reveal the effect of environmental factor on microbial community distribution in the sediment, the oxidation-reduction potential values in the seven regions were detected (Fig. 6). In regions (1), (2), and (3), the ORP values were approximately $-100 \mathrm{mV}$, and in 

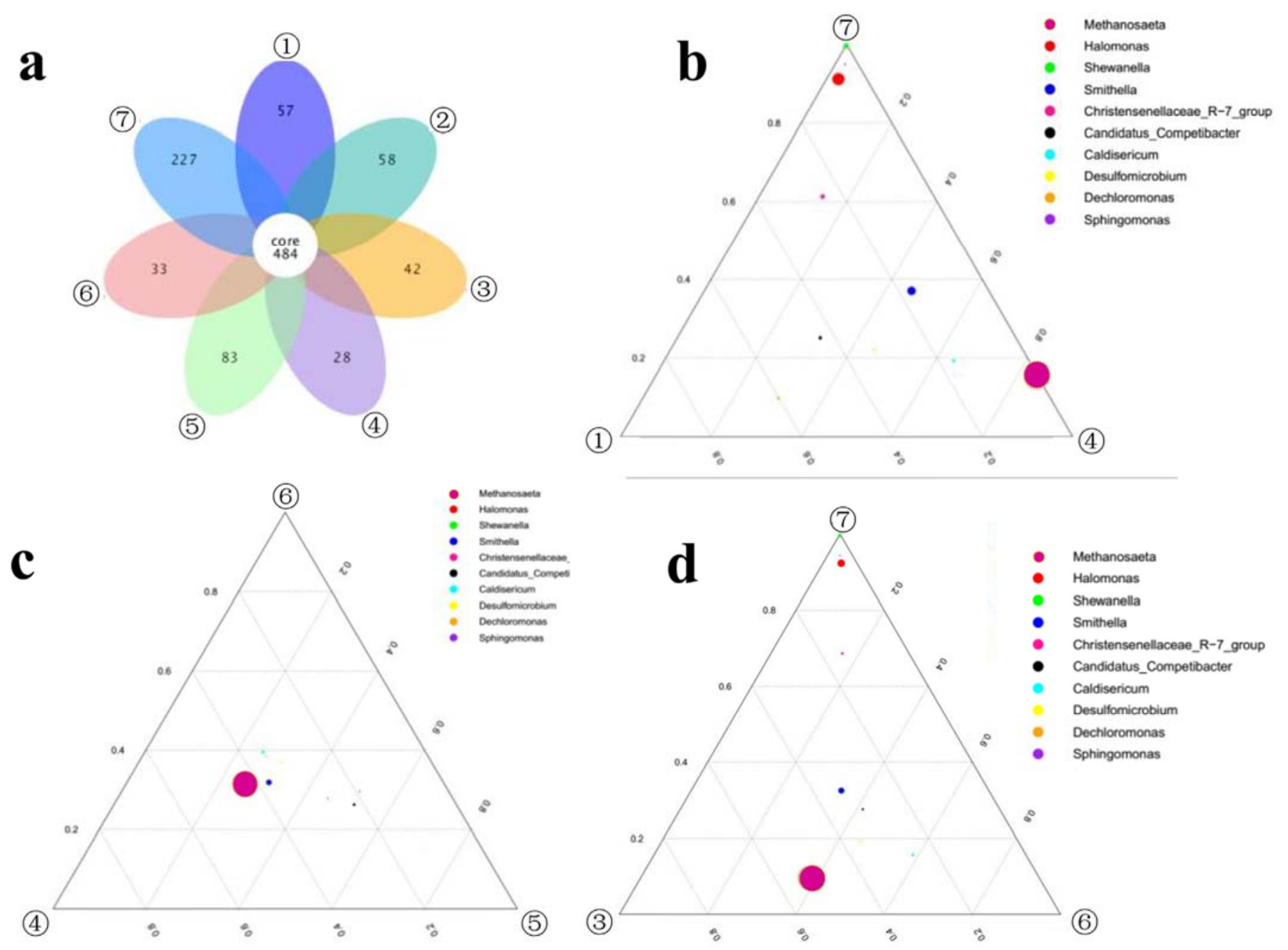

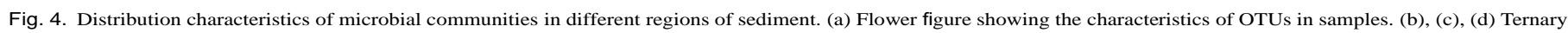

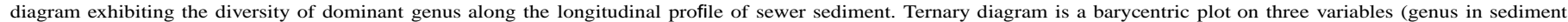

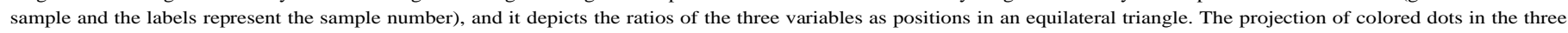
boundary of equilateral triangle show the relative proportion of genus in the three samples.

regions (4), (5), (6), the ORP values were lower than $-320 \mathrm{mV}$, and then, it were increased to $-284 \sim-300 \mathrm{mV}$ in region (7). In general, the ORP variation could affect the metabolism of methanogens and sulfate-reducing bacteria, although the methanogens could survive at the condition of higher ORP values (maximum of $-200 \mathrm{mV}$ ), the most suitable condition for reproduction of methanogens should be lower than $-300 \mathrm{mV}$ (Isa et al., 1986), while the ORP requirement for reproduction of sulfate-reducing bacteria is much higher than methanogens (maximum of $-100 \mathrm{mV}$ (Harada et al., 1994)), therefore, at the condition of relatively higher ORP values $(-200$ $\mathrm{mV} \sim-300 \mathrm{mV}$ ), the sulfate reduction process would be preferentially occurred than methanogenesis. Combining with the above discussion that accumulation rate of small molecule organic substrate in deep layer could be lower than that in middle layer, the condition of higher ORP values in region (7) could also provide suitable environment for sulfate-reducing bacteria reproduction processes, therefore, the sulfate-reducing bacteria were enriched in deep layer of sediment and hydrogen sulfide enrichment would inhibit the methanogenesis processes in this place. In conclusion, the methanogenesis and sulfate-reducing processes mainly occurred in middle and deep layer of sediment respectively, and the emission of methane and hydrogen sulfide was significant in sewer sediment (Supporting Fig. 1).

3.4. Contaminants and microflora evaluation in different regions of the sewer sediment

To further explain the contaminant distribution characteristics in the sewer sediment, Spearman analysis was conducted to determine the relationship between the functional genera and contaminant concentration in the seven regions. As shown in Fig. 7, the gridding with stars represents a significant positive or negative correlation between the contaminant concentration and functional genera in the regions. The functional bacteria for carbon pollutant transformation (C), mainly including fermentative bacteria, showed a positive correlation with TCOD and SCOD in all regions except region (1) (light blue stripe). The dominant fermentative genera, including Aquabacterium, Aeromonas, Paludibacter (Luo et al., 2014; Kalmbach et al., 1999; Ishii et al., 2014), were detected in all regions of the sediment (Supporting Table 2), which promote the processes of hydrolysis and acidification, indicating that fermentation was the major biochemical reaction in the sewer sediment; however, due to the turbulent state near the inner surface of the sewer, fermentation did not occur easily in region (1). 

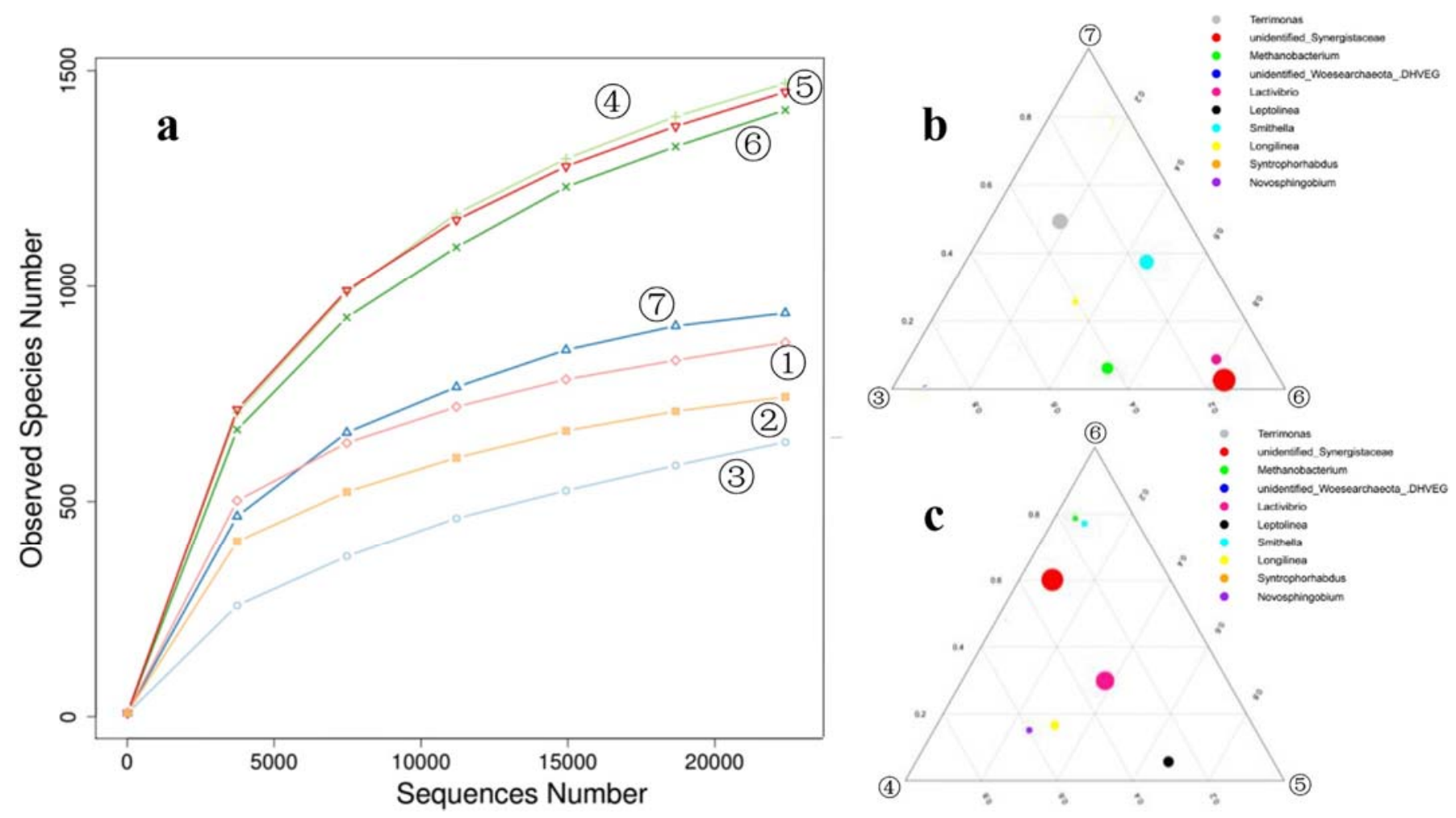

Fig. 5. Distribution of archaea in different regions of sediment.

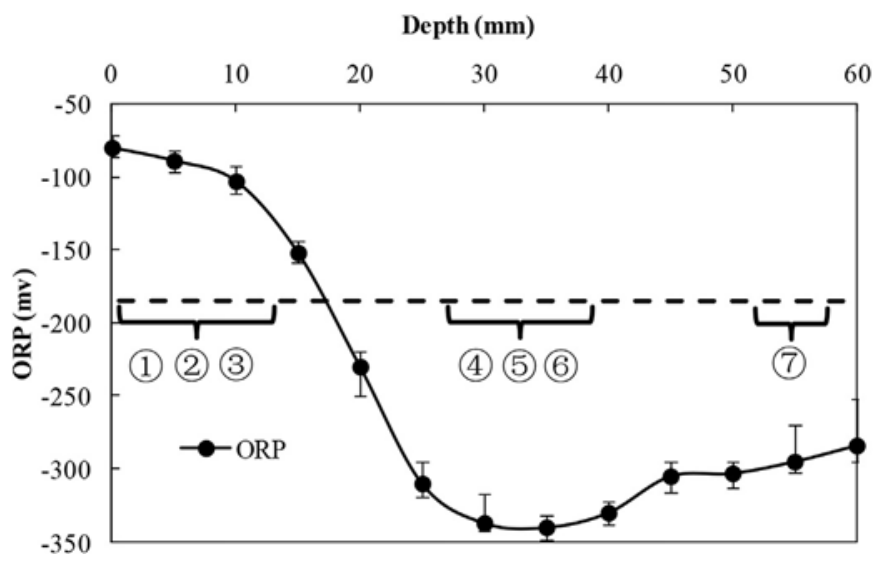

Fig. 6. Variation of ORP values in different regions of sediment.

The functional bacteria for nitrogen pollutant transformation (N) only exhibited a positive correlation with TN in region (1), and this result is in accordance with the sequencing detection of nitrifying bacteria and denitrifying bacteria. Due to the anaerobic environment in the sewer sediment, nitrifying bacteria nearly could not be found, except in region (1) (Nitrosomonas (Marsh et al., 2005) $0.15 \%$, Nitrosococcus (Garrity et al., 2004) $0.13 \%$ ). This may be due to the unstable sewage flow state near the inner surface of the sewer pipes, which supplied little oxygen to region (1). Dechloromonas, Alicycliphilus, and Thauera (Achenbach et al., 2001; Mechichi et al., 2003; Han et al., 2015) were detected in regions (1), (2), and (3) of the sediment, which leads to denitrification, and due to the lack of $\mathrm{NO}_{3}-\mathrm{N}$ in the sediment, the relative abundances of denitrifying bacteria were extremely low (Supporting Table 2). The lack of nitrate prohibited the metabolism of the functional bacteria for nitrogen pollutant transformation, and these kind of bacteria could only consume COD to maintain survival (showing a positive correlation with COD at the upper layer of the sediment (regions (1), (2), and (3)).

The functional bacteria for phosphorus pollutant transformation (P) showed a significant negative correlation with TP and $\mathrm{PO}_{4}-\mathrm{P}$ in most regions, except for region (2). In general, polyphosphateaccumulating organisms consist of two types of bacteria, denitrifying phosphorus-removing bacteria and aerobic phosphorusaccumulating bacteria (Ahn et al., 2002; Kuba et al., 1996), and because oxygen and nitrate act as electron acceptors for polyphosphate-accumulating organisms and aerobic phosphorusaccumulating bacteria, the diversity of polyphosphateaccumulating organisms was low in all regions (Supporting Table 2 ), and those microbial communities showed a non- significant correlation with phosphorus contaminants. It can be concluded that the increase in $\mathrm{TP}$ and $\mathrm{PO}_{4}-\mathrm{P}$ in the sediment may mainly be due to particulate matter deposition from sewage, and phosphorus transformation was difficult to achieve in the sewer sediment. The genera of methane-producing archaea showed a significant positive correlation with SCOD in regions (4), (5), (6), and (7), especially in the middle layer of the sewer sediment; therefore, the methane-producing process may be greatly promoted in the sediment. Thus, the Spearman analysis confirmed the distribution characteristics of archaea that were exhibited above.

In conclusion, fermentative bacteria play an important role in all regions of the sewer sediment to induce particulate matter hydrolysis and hydrolysate enrichment (accumulation of SCOD and SCFAs shown in Fig. 2(b)), which gives a proper fundamental understanding of the bioreactions involved in pollutant transformation. Previous studies have verified that the consumption of substrates by methanogens and sulfate-reducing bacteria is selective; therefore, the category and concentration of fermentation products in the different regions of sewer sediment affect the 


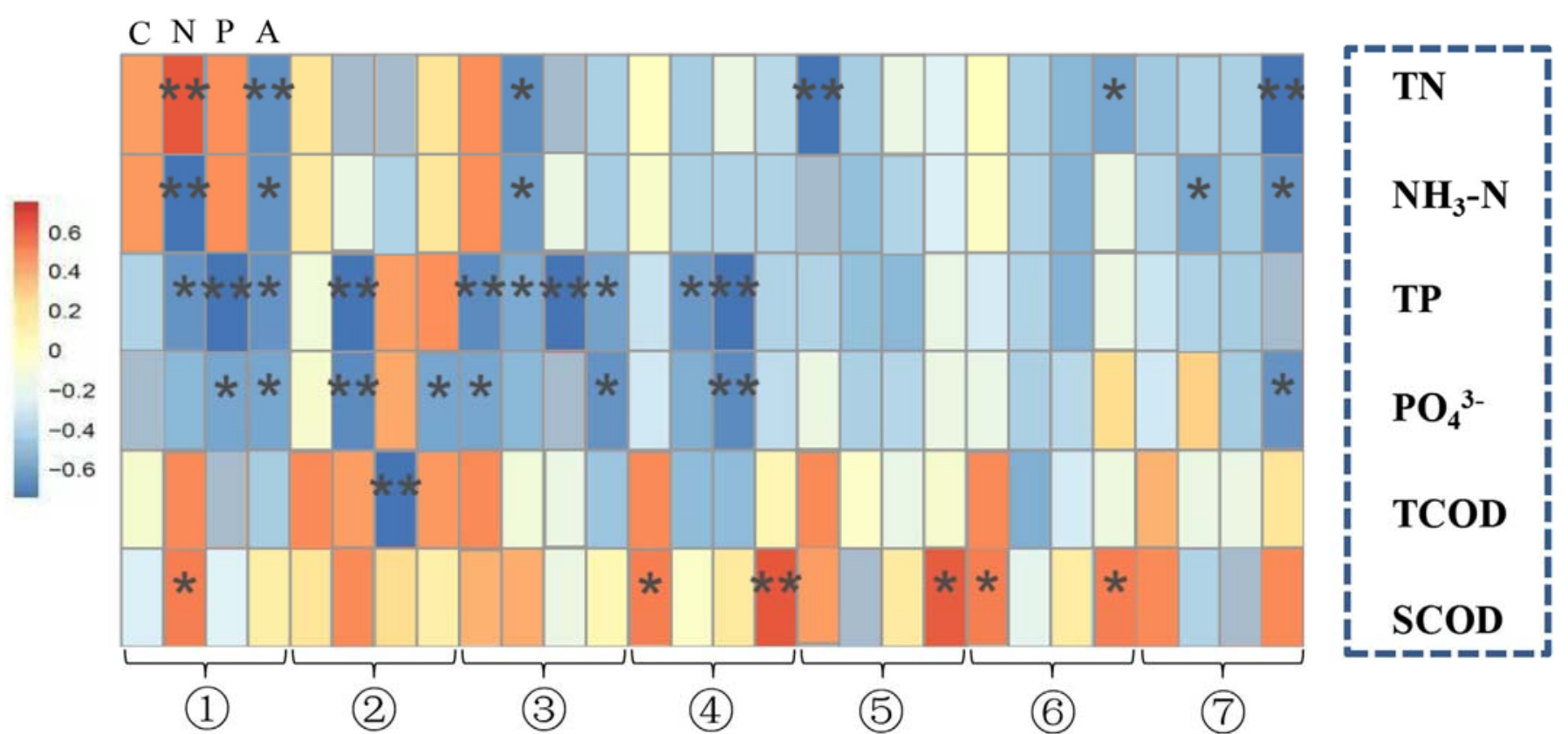

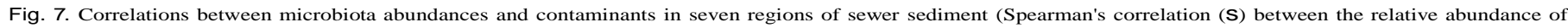

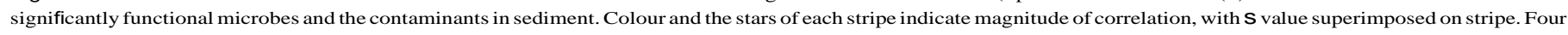
stripe sequences in each region indicate the functional microbes of carbon (C), nitrogen (N), phosphorus (P) transformation, methane-production archaea (A) in sequence (clas-

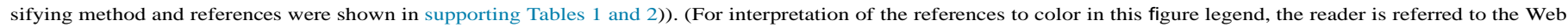
version of this article.)

metabolism of the two pivotal microbial communities. It caused the archaea and sulfate-reducing bacteria exhibited depth-dependent reproduction characteristics, which led to the emission of methane and sulfide in the middle and deep layer, respectively. In contrast to the enrichment of fermentative bacteria (including hydrolytic-acidification bacteria and methanogens) and sulfatereducing bacteria, nitrifying and polyphosphate-accumulating bacteria could only survive in the sediment, and showed a nonsignificant correlation with nitrogen and phosphorus matters, which indicates that the transformation of nitrogen and phosphorus contaminants was mainly caused by physical particulate matter deposition from sewage. In addition, fluctuating variations in nitrogen and phosphorus contaminants in sewer sediment could affect the quality of influent wastewater, and then might affect the treatment pressure in wastewater treatment plants, which should be verified in the future. Based on the functional evaluation of pollutant transformation in this study, a theoretical basis for optimizing the operation of urban sewer systems and predicting influent quality of wastewater treatment plants will be proposed.

\section{Conclusions}

Based on a pilot experimental sewer system, the pollutant transformation mechanism was studied in sediment. The main conclusions drawn from this study are as follows:

(1) Owing to the variation of ORP values in different longitudinal profiles and depths of the sediment, dominant functional microbial communities were found existing in distinct regions.

(2) The fermentative bacteria play an important role in all regions of the sewer sediment, and it could induce the accumulation of easily degradable substrates for diverse pollutant transformation in sewer sediment.
(3) Methanogens and sulfate-reducing bacteria exhibited depthdependent reproduction characteristics, which might led to the emission of methane and sulfide in the sediment of the middle and deep layer, respectively.

(4) Nitrifying and polyphosphate-accumulating bacteria could hardly survive in the sediment, which indicated that the variation of nitrogen and phosphorus contaminants might be mainly caused by the physical particulate matter deposition from sewage.

\section{Author contributions}

The manuscript was written by contributions of all authors. All authors have approved the final version of the manuscript.

\section{Acknowledgements}

This study was supported by the Shaanxi Science \& Technology Co-ordination \& Innovation Project (No. 2016TZC-S-19-3), National key research and development program (2016YFC0400701), the Program for Innovative Research Team in Shaanxi Province (PIRT) (No. 2013KCT-13). The authors are also grateful for the research collaboration between Xi'an University of Architecture and Technology and University of Technology Sydney.

\section{Appendix A. Supplementary data}

Supplementary data related to this article can be found at https://doi.org/10.1016/j.envpol.2018.03.007.

\section{References}

Achenbach, L.A., Michaelidou, U., Bruce, R.A., Fryman, J., Coates, J.D., 2001. Dechloromonas agitata gen. nov., sp. nov. and Dechlorosoma suillum gen. nov., sp. nov., two novel environmentally dominant (per) chlorate-reducing bacteria and 
their phylogenetic position. Int. J. Syst. Evol. Microbiol. 51 (2), 527e533.

Ahn, J., Daidou, T., Tsuneda, S., Hirata, A., 2002. Characterization of denitrifying phosphate-accumulating organisms cultivated under different electron acceptor conditions using polymerase chain reaction-denaturing gradient gel electrophoresis assay. Water Res. 36 (2), 403e412.

APHA, AWWA, WEF, 2002. Standard Methods for the Examination of Water and Wastewater. American Public Health Association, Washington.

Ashley, R., Crabtree, B., Fraser, A., Hvitved-Jacobsen, T., 2003. European research into sewer sediments and associated pollutants and processes. J. Hydraul. Eng. 129 (4), $267 \mathrm{e} 275$.

Caporaso, J.G., Kuczynski, J., Stombaugh, J., Bittinger, K., Bushman, F.D., Costello, E.K., Huttley, G.A., 2010. QIIME allows analysis of high-throughput community sequencing data. Nat. Meth. 7 (5), 335.

Chen, C., Ren, N., Wang, A., Yu, Z., Lee, D.J., 2008. Simultaneous biological removal of sulfur, nitrogen and carbon using EGSB reactor. Appl. Microbiol. Biotechnol. 78 (6), $1057 \mathrm{e} 1063$.

Chhetri, R.K., Bonnerup, A., Andersen, H.R., 2016. Combined Sewer Overflow pretreatment with chemical coagulation and a particle settler for improved peracetic acid disinfection. J. Ind. Eng. Chem. 37, 372e379.

Dinh, N.T., Hatta, K., Kwon, S.H., Rollon, A.P., Nakasaki, K., 2014. Changes in the microbial community during the acclimation stages of the methane fermen- tation for the treatment of glycerol. Biomass Bioenergy 68, $240 \mathrm{e} 249$.

EUZ'BY, J.P., 1997. List of bacterial names with standing in nomenclature: a folder available on the internet. Int. J. Syst. Evol. Microbiol. 47 (2), $590 e 592$.

Feng, L., Chen, Y., Zheng, X., 2009. Enhancement of waste activated sludge protein conversion and volatile fatty acids accumulation during waste activated sludge anaerobic fermentation by carbohydrate substrate addition: the effect of $\mathrm{pH}$. Environ. Sci. Technol. 43 (12), 4373e4380.

Garrity, G.M., Bell, J.A., Lilburn, T.G., 2004. Taxonomic Outline of the Prokaryotes Bergey's Manual of Systematic Bacteriology. Springer, New York, Berlin, Heidelberg.

Han, X., Wang, Z., Ma, J., Zhu, C., Li, Y., Wu, Z., 2015. Membrane bioreactors fed with different $\mathrm{COD} / \mathrm{N}$ ratio wastewater: impacts on microbial community, microbia products, and membrane fouling. Environ. Sci. Pollut. Res. 22 (15) $11436 \mathrm{e} 11445$.

Harada, H., Uemura, S., Momonoi, K., 1994. Interaction between sulfate-reducing bacteria and methane-producing bacteria in UASB reactors fed with low strength wastes containing different levels of sulfate. Water Res. 28 (2), $355 e 367$.

Henze, M., Harremo€s, P., 1983. Anaerobic treatment of wastewater in fixed film reactorsea literature review. Water Sci. Technol. 15 (8e9), 1 e101.

Hogan, M., 2010. Heavy Metal. Encyclopedia of Earth. National Council for Science and the Environment, Washington, DC.

Hvitved-Jacobsen, T., Vollertsen, J., Nielsen, P.H., 1998. A process and model concep for microbial wastewater transformations in gravity sewers. Water Sci. Technol 37 (1), $233 e 241$.

Isa, Z., Grusenmeyer, S., Verstraete, W., 1986. Sulfate reduction relative to methane production in high-rate anaerobic digestion: technical aspects. Appl. Environ. Microbiol. 51 (3), 572e579.

Ishii, S.I., Suzuki, S., Norden-Krichmar, T.M., Phan, T., Wanger, G., Nealson, K.H. Bretschger, O., 2014. Microbial population and functional dynamics associated with surface potential and carbon metabolism. ISME J. 8 (5), 963.

Jalliffier-Verne, I., Heniche, M., Madoux-Humery, A.S., Galarneau, M., Servais, P., Pr'vost, M., Dorner, S., 2016. Cumulative effects of fecal contamination from combined sewer overflows: management for source water protection. J. Environ. Manag. 174, 62e70.

Jin, P., Wang, B., Jiao, D., Sun, G., Wang, B., Wang, X.C., 2015. Characterization of microflora and transformation of organic matters in urban sewer system. Water Res. 84, $112 \mathrm{e} 119$.

Kalmbach, S., Manz, W., Wecke, J., Szewzyk, U., 1999. Aquabacterium gen. nov., with description of Aquabacterium citratiphilum sp. nov., Aquabacterium parvum sp. nov. and Aquabacterium commune sp. nov., three in situ dominant bacterial species from the Berlin drinking water system. Int. J. Syst. Evol. Microbiol. 49 (2) 769 e777.

Kuba, T.M.C.M., Van Loosdrecht, M.C.M., Heijnen, J.J., 1996. Phosphorus and nitroger removal with minimal COD requirement by integration of denitrifying dephosphatation and nitrification in a two-sludge system. Water Res. 30 (7), $1702 \mathrm{e} 1710$.

Lev'en, L., Eriksson, A.R., Schnürer, A., 2007. Effect of process temperature on bacterial and archaeal communities in two methanogenic bioreactors treating organic household waste. FEMS Microbiol. Ecol. 59 (3), $683 e 693$.

Liu, Y., Ni, B.J., Ganigué R., Werner, U., Sharma, K.R., Yuan, Z., 2015. Sulfide and methane production in sewer sediments. Water Res. 70, 350 e359.

Luo, J., Feng, L., Chen, Y., Li, X., Chen, H., Xiao, N., Wang, D., 2014. Stimulating shortchain fatty acids production from waste activated sludge by nano zero-valent iron. J. Biotechnol. 187, 98e105.

Mago T., Salzberg, S.L., 2011. FLASH: fast length adjustment of short reads to improve genome assemblies. Bioinformatics 27 (21), 2957 e2963.

Maillacheruvu, K.Y., Parkin, G.F., Peng, C.Y., Kuo, W.C., Oonge, Z.I., Lebduschka, V., 1993. Sulfide toxicity in anaerobic systems fed sulfate and various organics. Water Environ. Res. 65 (2), $100 e 109$.

Marsh, K.L., Sims, G.K., Mulvaney, R.L., 2005. Availability of urea to autotrophic ammonia-oxidizing bacteria as related to the fate of ${ }^{14} \mathrm{C}$-and ${ }^{15} \mathrm{~N}$-labeled urea added to soil. Biol. Fertil. Soils 42 (2), 137.

Mechichi, T., Stackebrandt, E., Fuchs, G., 2003. Alicycliphilus denitrificans gen. nov., sp. nov., a cyclohexanol-degrading, nitrate-reducing b-proteobacterium. Int. J. Syst. Evol. Microbiol. 53 (1), 147e152.

Mouri, G., Oki, T., 2010. Modelling sewer sediment deposition, erosion, and transport processes to predict acute influent and reduce combined sewer overflows and CO2 emissions. Water Sci. Technol. 62 (10), $2346 \mathrm{e} 2356$.

Muyzer, G., Stams, A.J., 2008. The ecology and biotechnology of sulphate-reducing bacteria. Nat. Rev. Microbiol. 6 (6), 441

Nelson, M.C., Morrison, M., Yu, Z., 2011. A meta-analysis of the microbial diversity observed in anaerobic digesters. Bioresour. Technol. 102 (4), $3730 e 3739$.

Ortiz-Alvarez, R., Casamayor, E.O., 2016. High occurrence of Pacearchaeota and Woesearchaeota (Archaea superphylum DPANN) in the surface waters of oligotrophic high-altitude lakes. Environ. Microbiol. Rep. 8 (2), 210e217.

Pender, S., Toomey, M., Carton, M., Eardly, D., Patching, J.W., Colleran, E., O'Flaherty, V., 2004. Long-term effects of operating temperature and sulphate addition on the methanogenic community structure of anaerobic hybrid reactors. Water Res. 38 (3), 619e630.

Qiu, Y.L., Hanada, S., Kamagata, Y., Guo, R.B., Sekiguchi, Y., 2014. Lactivibrio alcoholicus gen. nov., sp. nov., an anaerobic, mesophilic, lactate-, alcohol-, carbohydrateand amino-acid-degrading bacterium in the phylum Synergis- tetes. Int. J. Syst. Evol. Microbiol. 64 (6), 2137e2145.

Rao, M.S., Munoz, J., Stevens, W.F., 2000. Critical factors in chitin production by fermentation of shrimp biowaste. Appl. Microbiol. Biotechnol. 54 (6), 808e813.

Rotaru, A.E., Shrestha, P.M., Liu, F., Shrestha, M., Shrestha, D., Embree, M. Lovley, D.R., 2014. A new model for electron flow during anaerobic digestion: direct interspecies electron transfer to Methanosaeta for the reduction of carbon dioxide to methane. Energy Environ. Sci. 7 (1), $408 \mathrm{e} 415$.

Sharma, K.R., Yuan, Z., de Haas, D., Hamilton, G., Corrie, S., Keller, J., 2008. Dynamics and dynamic modelling of $\mathrm{H}_{2} \mathrm{~S}$ production in sewer systems. Water Res. 42 (10e11), 2527e2538.

Skipworth, P.J., Tait, S.J., Saul, A.J., 1999. Erosion of sediment beds in sewers: model development. J. Environ. Eng. 125 (6), 566e573.

Srinandan, C.S., Shah, M., Patel, B., Nerurkar, A.S., 2011. Assessment of denitrifying bacterial composition in activated sludge. Bioresour. Technol. 102 (20), 9481 e9489.

Tabatabaei, M., Rahim, R.A., Abdullah, N., Wright, A.D.G., Shirai, Y., Sakai, K. Hassan, M.A., 2010. Importance of the methanogenic archaea populations in anaerobic wastewater treatments. Process Biochem. 45 (8), $1214 \mathrm{e} 1225$.

Taylor, J., Parkes, R.J., 1983. The cellular fatty acids of the sulphate-reducing bacteria, Desulfobacter sp., Desulfobulbus sp. and Desulfovibrio desulfuricans. Microbiology 129 (11), 3303e3309.

Tsukamoto, T.K., Miller, G.C., 1999. Methanol as a carbon source for microbiological treatment of acid mine drainage. Water Res. 33 (6), 1365e1370.

Yassin, A.F., Inglis, T.J.J., Hupfer, H., Siering, C., Schumann, P., Busse, H.J., AravenaRomán, M., 2012. Cruoricaptor ignavus gen. nov., sp. nov., a novel bacterium of the family Flavobacteriaceae isolated from blood culture of a man with bacteraemia. Syst. Appl. Microbiol. 35 (7), 421 e426. 